Euskal ikerketen aldizkaria | Revue d'études basques |

Revista de estudios vascos | Basque studies review

19 | 2016

Numéro XIX

\title{
Etxepareren darauritzut eta Leizarragaren dauritzan, parez pare
}

Borja Ariztimuño

\section{OpenEdition}

\section{Journals}

Édition électronique

URL : https://journals.openedition.org/lapurdum/3106

DOI : 10.4000/lapurdum.3106

ISSN : 1965-0655

\section{Éditeur}

IKER

Édition imprimée

Date de publication : 1 janvier 2016

Pagination : 59-65

ISBN : 978-2-95534-134-6

ISSN : $1273-3830$

Référence électronique

Borja Ariztimuño, «Etxepareren darauritzut eta Leizarragaren dauritzan, parez pare», Lapurdum [Linean], 19 | 2016, Sarean emana----an 01 janvier 2021, kontsultatu 03 septembre 2021. URL: http:// journals.openedition.org/lapurdum/3106 ; DOI: https://doi.org/10.4000/lapurdum.3106 


\section{Etxepareren darauritzut eta Leizarragaren dauritzan, parez pare}

Borja ARIZTIMUÑO

Euskal Herriko Unibertsitatea (UPV/EHU)

Xarles Bidegainek jorraturiko hainbat eta hainbat gairen artean testu zaharrak eta dialektologia badirela profitatuz, bataren laguntzaz bestearen alderdi diakronikoari argi egiteko baliagarri gerta dakizkigukeen bi lekukotasun hauek izango ditut hizpide, llabur bezain zehatz izan nahi lukeen lan honetan (inolaz ere gaia agortu gabe, noski):

(1) a. (...) çuri neure iaun eta iabia beçala igorten darauritzut heuscarazco copla batzu (...) (Etxepare, 1545, Linguae Vasconum Primitiae-ko hitzaurrea)

b. Eta eguiteco huni dauritzan gaucetan complituqui informatua çarençát (...) (Leizarraga, 1571, Fedeco Confessionea liburuxkako Regueri eskaintza)

Esango nuke bi adizki horiek nahiko atzendurik egon direla, hiruzpalau aldiz bakarrik idoro baititut euskalaritzaren bibliografian. Etxeparerenaren lehen erreferentzia Victor L. A. Stempf-en 1887ko artikulu batean dago, non adizki bitxi honen osaera morfologikoa azaltzen saiatzen den (2). Hurrengo aipamena, adizki biena oraingoan, Hugo Schuchardt-ena da.

1. Eskerrak eman nahi dizkiet Joseba Lakarrari, Mikel Martínez Aretari eta Amaia Serranori, artikulu honen lehen idatzaldi bati egindako oharrengatik.

Lan honek hiru laguntza-iturri hauek izan ditu: 1) Joseba A. Lakarraren zuzendaritzapeko "Monumenta Linguae Vasconum IV: historia, crítica y edición de textos vascos" [FFI201237696] (Espainiar Gobernuko Hezkuntza eta Zientzia Ministerioak finantzatua); 2) Joaquín Gorrochateguik gidatzen duen "Historia de la Lengua Vasca y Lingüística Histórico-Comparada" (HLMV-LHC) [GIC 10/83, IT 486-10] (Eusko Jaurlaritzak finantzatua); 3) Miriam UribeEtxebarriak zuzenduriko "Hizkuntzalaritza Teorikoa eta Diakronikoa: Gramatika Unibertsala, Hizkuntza Indoeuroparrak eta Euskara" Heziketa eta Ikerkuntza Unitatea [UFI 11/14] (UPV/ EHUk finantzatua). 
Austriarrak Leizarragaren obrari eginiko aitzinsolas moduko hartan ageri da eta bertan haiek azaltzen ere saiatzen da, Stempfen bide beretik (3). Artikulu honetan erakutsi nahi dudanez, asmatzen ez dutelakoan nago. Hirugarrenez René Lafonek jaso zituen bere lanetan. Lehenik Leizarragaren dauritzan azaltzen du bere tesian, Schuchardt baino hobekixeago bideraturik, arazoak arazo ("dauritzan vient de *dagokitzan; l'r sert à empêcher le contact de $u$ et de i", Lafon 1943: 151). Etxeparerena, aldiz, aipatze hutsean uzten du ikertzaile gaskoiak 1951: 312, bestelako xehetasunik eman gabe. Patxi Altunak 1980: 6 paraturiko LVPren edizioan ere aurkitu dut adizki berori, baina euskara batuan dizkizut dela adierazten du soilki. Azkenik, Esther Zulaikak 1998: 254 bi formei egiten die erreferentzia bere tesiaren argitalpenean, berriz ere Leizarragarenetik abiaturik, Schuchardten hitzak (3) aipatuz.

(2) "Darauritzut. Ich habe sie (plur.) Ihnen. Igorten darauritzut, ich sende sie Ihnen; Analyse : $d$-arau-r-it-zu- $t=d+i t$, sie (Accusativ. pluralis); vgl. van Eys : Étude sur l'orig. et la formation des Verbes auxiliaires basques (1875), fol. 20 \& 5; -arau, Stamm mit Vokalwechsel des Verbum's : eroan, mitnehmen, mitführen, hier aber Hilfszeitwort im Sinne von izan, ukhan, haben ; $z u$, Ihnen (Dativ ohne die Endung ri) ; $t$, ich. Das $r$ zwischen arau und it ist zur Erleichterung der Aussprache eingeschoben. Vgl. van Eys (Grammaire comparée, fol. 330) : darozkitzut." (Stempf 1887: 15)

(3) "Está por dautzan = dagotzan (dagoca «se refiere a»). Exactamente lo mismo tenemos en Dechepare A II' 18 darauritzut por darautzut «yo os los he». La i procede de la marca de plural -it-<-ti- (vide Bask. St. I, 32 s.); la $r$ sirve para deshacer el diptongo, lo que es frecuente en vascuence: cf. loquerẽ en Voltoire (1642) por luqueen, p. 146 S." (Schuchardt 1989 [1900]: 51)

Hain oihartzun eskasaren askotariko arrazoiak bururatzen zaizkit. Baliteke azalgaitzegi gertatu izana hapax moduko adizkiok, edo/eta garrantzi txikikoak direla irizteagatik utzi izana bazterrean; orobat litekeena da azaltzeko beharrik ere inork sentitu ez izatea, adieraz bederen, eta hein batean formaz ere, aski argiak direla-eta. Ordea, nire ustez badute esatekorik euskal aditz jokatuaren garapenaz eta, azterketa sakonago bat eginez gero, baita agian euskalkien zatiketaz ere.

Hariari zirt edo zart heldu beharrez, esango dut adizkion interesgarritasuna ez datorrela soilik -ri- misteriotsu horretarik, eta jarraian zerrendatuko ditut puntuz puntu aztertu nahi ditudanak:
a. egon erroaren higadura (-u-)
b. egon-en - $(t) z(a)$ - pluralgilea
c. hirugarren pertsonaren datibo-komunztadura
d. *eradun-en objektu pluralgilea
e. *eradun-en datibo-komunztadurako aldaera afrikatua (-tzu-)
f. datibo-aurreko marka (Trask-en 1997: 227 dative flag delakoa)

Derradan, hasteko, hemen aurkeztuko dudan analisia ez dela behar lukeen edota nahi nukeen bezain sakona, ikuspegi orokor bat emateko xedea baitu. Hori esanda, eta 
(4)-n aipaturiko lehen puntuari (a) lotuaz, oro har, -u-dun aldaerak (oinarrizko nago, hago, dago formetarik kanpo) ekialdean zaharragotzat jotzen ditut (ez etimologikoki, jakina, baina forma lekukotu zehatzei dagokienez). ${ }^{2}$ Erdialderago, Aresoko otoitzetan nahiz Bretainiako kantuan, gaode eta daode bezalakoak lekukotzen dira, beti ere -de pluralgilearekin (ahozko testu zaharrak eta "buruz ikasiak" ziratekeela kontuan harturik, arkaismotzat har litezke). Mendebaldean, ostera, Lazarragak eta Landuccik -o-dunak dituzte gehienez ere (zaoz, daoden). Izan ere, Lazarragaren eskuizkribuan forma diptongodun ugari daude, gehiago izan arren - $g$ gorde dutenak (oinarrizkoak asko, jakina), mendebaldean gertatu ohi den bezala. Hala ere, badira nire corpusean -u- daukaten sartaldeko bi adizki, biak -ke atzizkiaz horniturik: baleuque 'balegoke'3 (RS 309) eta dauquezu 'dagokizuke'4 (Lazarraga A27). ${ }^{5}$

Hortaz, Leizarragak dauritzan baten ondoan zazpi dagozkan badakartza (eta cf. besteak beste Materraren dagotzan), lehenengoari zaharrago deritzot arestian aipatu zentzuan; jakina, sorburuan *-go- behar zuen.

Bigarren puntuaz den bezainbatean (4b), Ariztimuño 2015a: 67-n diodan bezala, badirudi inoiz -z(a) pluralgilea orokorra izan zela egon aditzean ere, ondoren hizkera gehienetan -de nagusitu bazen ere. Horren arrastoak Nor-Nori motako adizkietan gorde dira; esaterako, arestion aipatu ditudanetan. Aldaera afrikatuak hainbat azalbide izan litzake,

2. Nire adizki zaharren datu-basean (ca. 1625 arte) hauek topatu ditut: Rabelais (1542) nausu 'nagokizu', Etxepare (1545) dauke 'dagoke', daut 'dagokit', Leizarraga (1571) dauke 'dagoke', daut 'dagokit', dauku 'dagokigu', daue (eta dagote, dagozte) 'dagokie', nauzue 'nagokizue', aut 'hagokit' (baina dagoka, nagoka), Etxart (1616) nauke 'nagoke', Oihenart (1657, baina garbiro hizkera zaharragoa islatuz) dauke 'dagoke', dauko 'dagokio', auko 'hagokio'.

3. Lakarra 1996-n, ordea, eduki-ren adizkien artean sailkatzen da (cf. Aldai 1999: 384). Nire ustez, Errodrigo Zaratekoaren kantako baleduque bada eduki-ren adizki bat (ala *edun-ena?), baina RSetakoak arazo semantiko (podriase auer) eta formalak ('baleukate' edo 'balukete' bezalako plural inpertsonal gisa ulertuz gero, -ae edo -ee > -e gertatua zela onartu beharko genuke, bertako hizkeraren kontra; cf. genitibo -aen ugariak, lenaengo, quehea 'kea', leuquee 'lukete', etab.

4. Bigarren hori ediziogileek (Gidor et al. 2011: A27) *edun-en adizkitzat daukate ('dukezu'); aldiz nik, egon-entzat hartuko nuke, azalduko ditudan arrazoiongatik. Batetik, mendebaldeko -au- diptongoa 3. pertsonako adizkietan soilik gorde da lehen testuetarik (dau(-e) vs dot, dogu), eta huraxe ere, lekukoturiko geroaldiko forma bakarrean, monoptongaturik ageri zaigu -ke atzizkia gehitzean (RS 325 doque 'duke'). Bestetik, Lazarragaren sistema aztertuz gero, badakusagu sistematikotasun bat non egon aditzak -z(a) pluralgilearekiko eta -ke geroaldiko morfemarekiko formetan (beti) galtzen duen bokalarteko herskaria. Izan ere, bi salbuespen ditu bakarrik: ediziogileen zuzenketa batek sorrarazitako zagode (bide batez, -de pluralgilearekiko bakarra), eta B16ko nagoque (metrikaz gain, idatzaldi nagusitik ateko poema izatea ere kontuan hartu beharrekoa dateke). Areago, eskuizkribu osoko hirugarren salbuespen bat ere bada (ediziogileek ere nabarmentzen dutena), baina Lazarragarena ez den beste esku batek pasarte batzuk argitzeko (ironia eta anbiguotasunetik urrunduz) eginiko moldaketetan ageri da: hain zuzen ere asco dauqueçu senarric esaldia aldatzen du estao çure senarric idatziaz. Horrek lehen idatzaldian ere egon aditza erabili delako ustea indartzen bide du.

5. Nolanahi ere, mendebaldeko dagoz bezalako adizkiak "berrosatuak" direlako hipotesiaz, ik. Ariztimuño prestatzen. 
eta nahasgarri gerta daiteke orain denak banan-banan aletzea. Laburbilduz, -tz(a) aldaera testuinguru (morfologiko) horretan bertan sortu den ala bestetarik hedatua den da afera. Inoiz *dagoz 'daude' bezalako forma orokor bat izan balitz, pentsa genezake *dagotz bilaka zitekeela, euskararen joera ezagunari jarraiki (Mitxelena 1977 [1961]: 288-289). ${ }^{6}$ Bukaerako -a-, aldiz, hirugarren pertsonaren datibo-komunztadurari legokioke $(<-0$; cf. Leizarragaren beraren dagoka 'dagokio'). Horrekin hirugarren puntuari hel diezaiokegu (4c). Izan ere, erdi-ekialdeko autoreengan - $a$ aldaera hedatu da aditz batzuetan (zaika, derauzka, dauka...), egon-en NorNori motakoetan bezala. Pluralgilera itzuliaz, pentsa bageneza "dago : *dagoz (a)"-ren ondoan "dagoka : X" bazela, orduan X horren osatzeko esan genezake bi aukera ziratekeela, oinarritzat dago-PL ala dago-DAT hartzen dugun. Lehenari dagokio, noski, Leizarragak badarabilen dagozka (<*dago-z-g(i)-o-) forma; bigarrenari, *dago-g(i)-z-a lekukotugabea, fonologikoki dagotza eman zezakeena (cf. zaizka, daduzka, derauzka vs. zaitza, dadutza, derautza eta, pluralgilearen eta beste morfemen arteko ordena ezberdinetarako, Aresoko otoitzetako diztegun vs. diezkun 'dizkiegun' aldaeren azalpena Ariztimuño 2015a-n).

Laugarren puntuari dagokionez (4d), Stempfek darauritzut-entzat eta Schuchardtek adizki berarentzat eta dauritzan-entzat proposaturiko azterketa morfologikoa (erroaren ondotik kokatuz it pluralgilea) onartzeko arrazoirik ez bide da, arestian azaldurikoa (-tz (a) pluralgileaz) eta hurrengo puntuan erakutsiko dena kontuan hartuz gero. Orobat esan beharrik ez bide dago Schuchardten azalpen fonologikoa (it $>$ ti... > i / V_?) ezin gerta dakiokeela asebetegarri euskararen bilakaeraz zerbait dakienari (hark Mitxelenaren FLV oinarrizko eta ezin utzizko lana ezagutu ez izanak, kronologia arazoak medio, ez liguke horrelakorik barkarazi behar, hala ere $)^{7}$

Beraz, non da darauritzut adizkian hain garbi aditzen dugun pluraltasunaren marka? Bada, hurrengo puntuarekin lotuz (4e), erdi-ekialdeko hainbat autorek datibo zein objektu pluraleko komunztadura (nahiz biak batera) daukaten adizkietan analogiaz orokorturik darabilten -tzu aldaeran gorderik, zeina sortu baitzatekeen, besteak beste, pluralgilea eta bigarren pertsonaren marka baturik $(-(t) z+-z u>-t z u)$, zubereraz egun ere den bezala. "Besteak beste" esan dut, uste baitut, Ariztimuño 2015-eko proposamenei jarraiki, - $k$ (i)-morfemak ere ikustekorik izan zezakeela (derautzut < *deraukzut, adibidez; berriz ere, derauzkizut bezalako adizkiak "berregintzat" jotzeko aukera legoke), eta hortik -tzu aldaera datibotasunarekin nahiz pluraltasunarekin lotzeko joera. ${ }^{8}$

Azken punturako utzi dut, hortaz, adizkion zati ilunena (-ri-); eta irakurlea konturatuko

6. Egia da, Mikel Martínez Aretak gogorarazi didanez, joera horrek salbuespen nabarmenak dituela, -z instrumentala kasu (eta maiz edo ez bezalako hitzak; cf. halaber naiz, baina balitz). Ildo horretatik, errazago izan liteke onartzea ordurako bazela -tza alomorfo bat (Camino 2013: 110, 28. oin-oh.) ikusirik diotza 'dizkio' bezalako adizki zaharrak azaltzeko behar dukegula (ez bada horraino derautza eta dadutza bezalakoetarik analogiaz hedatu; cf. testuan jarraian ematen den azalpena -tza datibodun amaierako adizki horientzat).

7. Schuchardtek lege fonetikoez eta oro har hizkuntzaren erregulartasunez zituen usteei buruz ik. Lakarra 2003: 10-13.

8. Esango nuke mendebaldean ere gertatu zatekeela pluralgilearen desagertzerik *edutsi laguntzailearen txistukariak asimilaturik. 
zen, halaber, pluraltasunaren ezaugarri ez bada datibotasunari lotu beharrean garela (4f). Erraz da ikusten -i- horrekikoa, ${ }^{9}$ baina, $-r$-a epentesi hutsa ote da, aurreko ikertzaile zenbaitek proposatu bezala? Ez dut uste: euskararen barneko beste bilakaera baten aurrean gaudela begitantzen zait, zeina (itxura batean) erregularra izan ez arren, paraleloak badituen, bai eta beste bilakaera batekiko loturaren bat ere, Joseba Lakarrak iradoki didanez. Proposatzen dudana hau da: dauritzan eta darauritzut adizkietako -ri- morfema oso bat dela, <-gi- hain zuzen ere, -ki-ren aldaera zaharra (cf. egogi : egoki, edugi : eduki, ${ }^{10}$ etab.; Trask 1995). Izan ere, $-\mathrm{VgV}->-\mathrm{VrV}$ - zenbait hitzen bilakaera eta etimologietan proposatua izan da (argienetako batzuk aipatzearren, arate < agate < a(h)ate, sorotsi zorotzi < so egotzi dela, cf. Mitxelena 1977 [1961]: 286, 12. oin-oh., eta hor ditugu Lakarraren 2009: 584 proposamena ulertu < *urertu : igerri bikotearen loturaz, edo Mitxelena 1977 [1961]: 339 eta Hualde 2005: 300 kontuan hartuz belarri < *berarri < begarri < bearri < beharri < *beha-(g)arri). Are gehiago, Lakarrak berak diostanez, baliteke beste bilakabide baten "ispilu-irudi" moduko bat izatea, hain zuzen ere konposaketako - $r \#>$ - $h \#$ zaharrarena (cf. Lakarra 2015: 355, eta han aipatzen den Mitxelena 1977 [1961]: 337).

Horrenbestez, bestelako proposamen hoberik ezean, "etimologia" hauek proposatzen ditut Etxepareren eta Leizarragaren adizki bakoitzok azaltzeko:

9. Nahiz eta datibo-aurreko markaren alomorfo hau ez den ohikoena (ia guztiz ezezaguna, izan ere, egon-en eta *eradun-en adizkietan). Morfema honen beste agerpen bitxi baterako (eta horrelakoetarik ondoriozta daitekeenaz) ikus Ariztimuño 2015b.

10. Ariztimuño 2013: 138, 38 oin-oh.-ean erauki eta hitzeraduki lexikalizatuak (OEH s.v.) aipatzen eta proposatzen ziren laguntzaile ditrantsitibo gisa gramatikalizaturiko eta *eradun gisa berreraiki eta aipatu ohi den aditzaren "egiazko" formatzat, *edun-en kausatiboak laguntzaile gisa gramatikalizatu aurretik zukeen esanahitik azal daitezkeela argudiaturik (cf. Mounole 2015). Aldiz, OEHk dakarren beste eraduki berriagoa litzateke, esanahi aldetik gardenagoa den heinean ('tener, mantener' hiztegiaren arabera, beharbada hobeto 'hacer mantenerse'; cf. s.v. eduki laugarren adiera, kontuan harturik lehen hirurak batera eman litezkeela, laugarren hau izanik bereziena).

Bada, erka bedi Nafarroa ekialde muturrean lekukoturiko era(u)gi eragu aditzarekin (OEHk 'traer' adieraz dakarrena). Izan ere, antzekotasunak antzekotasun, ez dut uste hura egar(r)i ('soportar', 'utilizar') ezagunxeagoarekin loturarik duenik, esaterako metatesi bidez-edo. Azken hori, zehazki, ekarri-ren aldaera zaharra dela esango nuke, edo etimologikoki lotuak daudela behinik behin.

Beraz, testuan aipatu bezalako bikoteei erauki : eraugi parea gehitzeko moduan garela pentsatzen dut. 

a. darauritzut $<* d a^{11}-$ rau-gi-z-zu-t
b. dauritzan $<*$ da-go-gi- $(t) z-0-(a) n^{12}$

\section{Erreferentziak}

Aldai, Gontzal. 1999. Notas sobre la última edición de los Refranes y Sentencias de 1596. Fontes Linguae Vasconum 82. 383-392.

Altuna, Patxi. 1980. Linguae Vasconum Primitiae. Edizio kritikoa. Bilbo: Euskaltzaindia - Ediciones Mensajero.

Ariztimuño, Borja. 2013. Euskal aditz jokatuaren osaeraz eta jatorriaz zenbait ohar. In Ricardo Gómez, Joaquín Gorrochategui, Joseba A. Lakarra \& Céline Mounole (arg.), Koldo Mitxelena Katedraren III. Biltzarra, 41-60. Vitoria-Gasteiz: UPV/EHUko Argitalpen Zerbitzua.

Ariztimuño, Borja, 2015a. Axularren -(k)aio aditz-bukaeraz: datibo(-ikurr)aren eta denbora-aspektu-moduen historiarako gaiak. Euskal hizkera eta dialektoak gaur egun (Lapurdum, ale bereziak 3), 81-113.

Ariztimuño, Borja. 2015b. Lazarragaren eskuizkribuko adizki batzuez (euskal aditz jokoaren kronologia erlatibo baterantz). In Maria-José Ezeizabarrena \& Ricardo Gómez (arg.), Eridenen du zerzaz kontenta: sailkideen omenaldia Henrike Knörr irakasleari (1947-2008), 117 140. Bilbo: UPV/EHUko Argitalpen Zerbitzua.

Ariztimuño, Borja, prestatzen. Euskarazko jarrera-aditz batzuen arteko harremanez. UPV/ EHUko izkribu argitaragabea.

Camino, Iñaki. 2013. Euskalkien historiaz: Lapurdi eta Nafarroa Garaia. In Ricardo Gómez, Joaquín Gorrochategui, Joseba A. Lakarra \& Céline Mounole (arg.), Koldo Mitxelena Katedraren III. Biltzarra, 77-140. Vitoria-Gasteiz: UPV/EHUko Argitalpen Zerbitzua.

Hualde, José Ignacio. 2005. Azentua eta etimologia. In Euskaltzaindia (arg.), Nerekin yaio nun (= IKER 17), 297-303. Bilbo: Euskaltzaindia.

Lafon, René. 1943. Le système du verbe basque au XVIème siècle. Bordele: Delmas.

Lafon, René. 1951. La langue de Bernard Dechepare. Boletín de la Real Sociedad Vascongada de Amigos del País 7: 3. 309-338.

Lakarra, Joseba A. 2003. Hacia un nuevo paradigma etimológico vasco: forma canónica, filología y reconstrucción. ASJU 37: 1. 261-391.

Lakarra, Joseba A. 2009. Adabakiak/h/-aren balio etimologikoaz. ASJU 43. 565-596.

Lakarra, Joseba A. 2015. Hiru hasperen haboro. In Maria-José Ezeizabarrena \& Ricardo Gómez (arg.), Eridenen du zerzaz kontenta: sailkideen omenaldia Henrike Knörr irakasleari (19472008), 349-378. Bilbo: UPV/EHUko Argitalpen Zerbitzua.

Mitxelena, Koldo. 1977 [1961]. Fonética Histórica Vasca (2. argitalpena). Donostia: Gipuzkoako Foru Aldundia [berrargit. in J. A. Lakarra \& I. Ruiz Arzalluz (arg.). 2011. Luis

11. Alde batera utzi dut, azterketa honetan, derau-vs. darau- aldakortasunaren afera.

12. Nahikoa litzateke berez $-n$ horrekin, baina adizkiaren zahartasunak - $a$ - bokaldun aldaera ene ustez zaharragoa ere kontuan hartzera narama (cf. Ariztimuño 2013: 53-56); azken emaitza, edonola ere, berdina litzateke. 
Michelena. Obras completas, vi. liburukia. Vitoria-Gasteiz - Donostia: UPV/EHU - Gipuzkoako Foru Aldundia].

Mounole, Céline. 2015. Datibo-komunztaduraz eta laguntzaile hirupertsonalen diakroniaz. In Beatriz Fernandez \& Pello Salaburu (arg.), Ibon Sarasolari Gorazarre. Homenatge, Homenaje, 473-490. Donostia: UPV/EHUko Argitalpen Zerbitzua.

Schuchardt, Hugo. 1989 [1900]. Introducción a las obras de Leizarraga [I. Ruiz Arzalluz eta J. M. Vélez Latorreren itzulpena] (= ASJUren gehigarriak XII). Donostia: Gipuzkoako Foru Aldundia.

Stempf, Victor L. A. 1887. Commentar und Glossar zu Bernard Dechepare's Baskischen Poesien (1545). Revue de Linguistique et de Philologie Comparée 20. 4-22.

Trask, R. L. 1997. The History of Basque. New York: Routledge.

Zulaika, Esther. 1998. Ioanes Leizarragaren aditza. Bilbo: Deustuko Unibertsitatea. 